\title{
The impact of gender images in commercials on the self-consciousness of adolescents
}

\author{
Olga G. Lopukhova \\ Kazan Federal University, Kazan, Russia \\ Corresponding author. E-mail: olopuhova@rambler.ru
}

Television has a strong impact on gender-identity development. Theoretical analysis shows that the direct perception of different gender characteristics in advertising images has a specific impact on gender self-consciousness, primarily at the unconscious level. The purpose of our study was to uncover features of this impact.

In this study, the effects of advertising images on the gender self-consciousness of teenagers were investigated. Two hypotheses were examined: (1) Perception of gender images in TV commercials has individual variability and is connected with gender features of self-consciousness (gender type of personality, gender differentiation of consciousness, the specifics of gender identification). (2) Direct perception of gender images in TV commercials has a differential influence on the transformation of verbal (cognitive) and nonverbal (emotive) levels of selfconsciousness.

The commercials, which were for chocolate, contained different gender types of male and female images (masculine female images, androgynous images, and feminine male images); they used as stimulus materials in an experimental situation involving 61 teenagers. The contents and dynamics of gender self-consciousness in adolescents were investigated using the psychosemantic method of "multiple identifications."

We discovered that the girls' preferences for gender images were more varied than those of the boys. Despite different variants in the gender characteristics in the advertising images, their impact on the gender self-consciousness of the adolescents consisted mostly of gender differentiation and identification with the images of their own gender. In general, in regard to the direct impact in the experimental situation, at the cognitive level, the girls revealed changes in the enhancement of gender identification with images of their gender, and the boys were characterized by the enhancement of gender differentiation. At the level of emotive evaluation, in contrast to the cognitive level, we observed stronger dynamics of the changes in selfconsciousness (enhancement of gender differentiation and enhancement of identification with images of ideals and parental images).

The results clearly showed the quite high plasticity of self-consciousness structures and their susceptibility to externally designated images. We concluded that, in their direct perception, features of gender images in TV commercials have specific effects on the consciousness of adolescents: they reinforce already-formed gender categories and self-identification. We consider this research a pilot study, and we are planning to check the results on a more representative sample with different age groups.

Keywords: commercials, gender images, identification, gender self-consciousness, adolescent 


\section{Introduction}

In contemporary society, television has a strong impact on a person's socialization. A number of studies have shown that television is quite important in forming social attitudes (Gladkova, 2013), and even short-term viewing of news messages has a significant influence on individual consciousness (Lavrova \& Matveeva, 2012). Great attention is paid to the analysis of advertising images, which often have a gender context (Barner, 1999; Bretl \& Cantor, 1988; Collins, 2011; Signorielli, 1989). Advertising, a system for representing objects, not only programs a consumer for the purchase of goods but is also an ideological construct symbolically defining cultural standards of behavior and relations. In this context advertising not only reproduces but also creates certain gender stereotypes (Gerbner, 1999; Pollay, 1986). Researchers believe that advertising images refer viewers to vague and not obvious sense codes that have primary meaning for their personalities because they influence attitudes and identity formation. Gender figurativeness always engenders viewer interest and is used in advertising materials because belonging to a certain gender is the deepest, most basic characteristic of a person (Garst \& Bodenhausen, 1997; Morgan, 1982). We agree with Collins (2011), who thinks that gender images in the media have been analyzed well enough at the moment and now it's time for the next stage of research - exploring comprehensively the impact of gender images on audiences.

At present it is impossible to estimate the character of gender constructs transmitted by the media on a unilateral basis. The rather popular previous view that the display of gender relations in advertising affects viewers' stereotyped views of gender roles, in which women are, traditionally, the object of men's desire (Ganahl, Prinsen, \& Netzley, 2003), is not fully confirmed now. The aim of advertisers is to create potential and attractive images of surrounding reality. For this reason advertising borrows images and models of social behavior in everyday life; these images present variously transformed gender norms and views, and, as a result, gender images of advertising products also become diverse (Collins, 2011).

At the same time one of the consequences of advertising is devaluation of gender values (Maksimova, 2005). Key notions of gender relationships and values can be taken as nonserious because of their rigid, grotesque, and inadequate application in media; thus, advertising can not only establish gender stereotypes but also transform gender guidelines, and innovative gender images can become embedded in individual consciousness.

In this respect interest arises in the mechanisms of gender identification and the transformation of self-consciousness under the impact of advertising images. In particular the following questions arise: Is the selective preference for advertising images connected with gender self-consciousness? Does the perception of advertising images cause changes in gender self-consciousness?

A study of these issues revealed that the impact of advertising images on viewers' identity is ambiguous and variable because it is determined by a number of factors (Durkin, 1985). Some researchers have found connections among viewers' gender attitudes, adherence to traditional or unconventional gender stereotypes, and personal gender stereotyping of TV images and identification with them (Duncan, Peterson, \& Winter, 1997; Oliver \& Sargent, 1998; Ruble \& Stangor, 1986; 
Signorella \& Liben, 1984). At the same time there are discrepant data about the nature of the impact of media images on gender-identity transformation. Eisenstock (1984) found that boys and girls with feminine preferences tend to identify more with a male counter-stereotypical portrayal than do masculine children. Richter, Appel, and Calio (2014) examined the influence of stories on the self-concept of femininity and found that reading a story that featured a protagonist with a traditional gender role (focused on motherhood) caused femininity to increase among respondents who were unlikely to engage in social comparison (had no children of their own), whereas no such effect was observed for respondents who had children of their own.

Theoretical analyses show that direct perception of different gender characteristics of female and male images in commercials has a specific impact on gender self-consciousness, primarily at the unconscious (emotive) level. In particular, our experiment examined the following hypotheses:

1. Perception of advertising gender images has an individual variability and is connected with gender features of self-consciousness.

2. Direct perception of gender images in TV commercials has a differential influence on the transformation of verbal (cognitive) and nonverbal (emotive) levels of self-consciousness.

\section{Method}

\section{Participants}

Adolescents were the participants of the experiment because at this age they are more sensitive than people of other ages to social patterns and models of gender self-consciousness and identity formation. The experiment was performed at secondary comprehensive schools in Kazan. To confirm the reliability of the results, the experiments was performed twice with different groups from different schools. Students took part in the experiment on a voluntary basis; the 61 students ( 29 boys and 32 girls) were 15 to 17 years old.

\section{Design of experiment}

The experiment had two stages. In the first stage gender characteristics of the selfconsciousness of each participant were discovered using the "multiple-identifications" method. The second stage of the experiment was conducted a week later. The participants were shown five selected commercials with different types of gender images. The participants watched all the commercials and selected the commercial and the image (female or male) they liked; then their gender characteristics were measured again. A new task was added to the procedure: participants had to rate the image that they liked in the commercial according to given scales. Changes in the character of gender self-consciousness were discovered by comparing the results obtained before and after the presentation of the commercials.

Commercials for chocolate were used as stimulus materials because this product is of interest to adolescents and is aimed at both female and male audiences. The five commercials were selected on the basis of certain criteria. All the commercials were well known by the participants as they were shown on popular TV channels 
during prime time. In each of the commercials female and male images interacted with each other. All commercials did not advertise the product from an information perspective (they did not state the advantages and quality of the product itself). Instead, they used primarily gender semantics to motivate a consumer's interest in the product. Most characters were close to the participants' age but a little older. This feature was chosen in order to promote identification.

The selected commercials portrayed different variants of gender type and their relationships:

1. The advertisement for Alpen Gold-tango portrayed androgynous female and male images and an egalitarian (modern) gender relationship. This was a commercial for black and white chocolate. In it a young girl and boy "fight" for a bar of chocolate during a dance, and neither of them wants to give up. Each presents a combination of gracefulness, sensuality, sexuality, and at the same time assertiveness, aggressive rivalry, and persistence to succeed.

2. The advertisement for Alpen gold-dark chocolate portrayed a nondifferentiated male image and a masculine female image. In the commercial a girl displays much activity and independence. From the balcony of an apartment the girl sees a handsome guy who is fixing a sign for Alpen Gold chocolate. The girl resolutely climbs down the water pipe in front of the amazed guy and runs past him: she does not need this guy, she needs chocolate. The girl gets it in a self-determined but risky manner. The boy does not demonstrate any special gender qualities. He is only amazed at the unexpected behavior of the girl.

3. The advertisement for Korkunov chocolates portrayed a feminine female image and a masculine male image in a traditional relationship. In a museum of classical paintings and sculptures a man of middle age, handsome and presumably rich and of high social status, offers a young, strange, nice girl a taste of the sweets with the words "Do you like classics? Taste this." Flirtation is clearly the basis of the characters' relationship: a self-confident man's win over a woman.

4. The advertisement for Milka milk chocolate portrayed both feminine female and male images and feminine relationships. Against a background of the Alps, a boy and a girl are hugging tenderly, demonstrating a state of bliss and serene happiness after having tasted the chocolate.

5. The advertisement for Snickers chocolate bars portrayed masculine male and female images and a modern relationship. Two boys and a presumably famous ballet dancer in a tutu are playing basketball. The ballet dancer is portrayed rather toughly. She is knocked off her feet. Rising up, she answers rather rudely her companions' taunt "What is this, a ballet? Play more severely." She eats a chocolate bar and transforms into a guy ready to play basketball in a tough, male manner.

\section{Method of diagnosis}

Diagnosis of the gender characteristics in the self-consciousness of the experiment participants was performed using the multiple-identifications method (Petrenko, 2010). The goal of the method is to rank role positions (in this study, images of gender identification) according to certain parameters. In this case, the following role positions were offered: 
- "Me in the present" (self-image)

- "Me in the future"

- "My father"

- "My mother"

- "An ideal man from my point of view"

- "An ideal woman from my point of view"

- "A typical modern man"

- "A typical modern woman"

- "A traditional man (as I view him)"

- "A traditional woman (as I view her)"

- "An image in the commercial that I like" (offered during the second phase of the experiment)

The procedure for measuring the gender characteristics in self-consciousness consisted of two parts. In the first part, the respondents had to rate 27 items (gender characteristics of personality) for each role position. The characteristics were taken from the Bem Sex Role Inventory questionnaire revalidated in compliance with Russian culture (Lopukhova, 2013). In this questionnaire the Masculinity, Femininity, and Neutral subscales accord with contemporary gender stereotypes in Russian society. The Masculinity and Femininity subscales (factors) indicate stereotypical personality traits, and the Neutral subscale includes traits common for both men and women. Each of the subscales includes 9 items. Samples of the Masculinity items are "brave," "having a strong personality," "forceful," "having the ability to be at the head," "dominant." Samples of the Femininity items are "compliant," "shy," "tender," "compassionate," "soft-spoken." The items were arranged on the 5-point Likert-scale (from 1 - "characteristic is not evident" to 5 - "high degree of evidence of characteristic"). To calculate subscale scores, the sum of the scores of the items was divided by the number of items in each subscale.

In the second part, the same role positions were estimated by ranking eight given colors (dark blue, green, red, yellow, violet, brown, black, and gray) in accordance with the color each role position is associated with. The Color Test of Relationships (Etkind \& Bazhin, 2000), which is the basis of this part of the diagnosis, has as a foundation the belief that essential relationships of nonverbal components of attitudes to other, essential ones and to oneself are reflected in their color associations. Color sensory ability is closely connected with the emotive component of the psyche and thus has been used in projective and psychosemantic approaches to diagnoses. The respondents chose the scale numbers used to evaluate gender images by using computers in a computer classroom.

The gender characteristics in the self-consciousness of the participants were discovered through their identification with certain gender images. Intercorrelation analyses were conducted separately of all the scale numbers chosen by each respondent for the first and second parts of the questionnaire. A positive correlation coefficient showed identification with the images in a respondent's consciousness; a negative correlation coefficient showed no identification with the images. In particular, a correlation coefficient in the range $1 \geq r \geq 0.6$ reflected 
close identification with the image; $0.5 \geq r \geq 0.3$ reflected some identification; 0.2 $\geq r \geq 0$ indicated no identification; $r \leq 0$ showed the contraposition of the images in consciousness. In addition, the ranking of each image on the Masculinity and Femininity scales and their mutual positions in this semantic space (according to the data from the first part of the questionnaire) were measured; this procedure provided the opportunity to detect the gender characteristics in the self-consciousness of each participant.

\section{Results}

According to the results of the diagnosis at the cognitive (verbal) level, the gender identification of most participants corresponded to their gender. The results of the first part of the questionnaire showed that the self-consciousness of most participants was gender-differentiated. Gender-differentiated consciousness manifested itself in the men's and women's images, which the respondents evaluated differently. Features of their identity on many items of the Masculinity and Femininity subscales were highly correlated. Thus, most of the participants had a firm self-assessment. As an exception, one boy did not have a differentiated gender self-consciousness as was manifested in his low estimations of gender features and absence of identification with both male images ("an ideal man," "my father," "me in the future") and female images. Another boy had feminine characteristics of self-consciousness: a high estimation of self-image on the Femininity subscale and self-identification with female images.

The results of diagnosing gender identification with the color-associations method gave another picture of many adolescents' self-consciousness. At the emotive level some girls showed diffuse gender identification: they identified with both female and male images. Rather often we observed the father's image perceived as feminine and strongly identified with female images ("an ideal woman," "a traditional woman"), and the mother's image perceived as being close to both the male and the female ideal images.

At the emotive level of boys' gender consciousness, identification with the mother's image was typical and was rather strong in some boys, and at the same time a gender-undifferentiated attitude to other images was present.

At the second stage of the experiment, when adolescents selected a commercial and an image, participants' preferences divided as shown in Table 1.

Table 1. Frequency distribution of choices of commercial by girls and boys

\begin{tabular}{lcc}
\hline Commercial for chocolate & \multicolumn{2}{c}{ Number of choices } \\
& Girls $(\mathbf{n}=\mathbf{3 2})$ & Boys $(\mathbf{n}=\mathbf{2 9})$ \\
\hline Milka & 8 & 1 \\
Snickers & 4 & 27 \\
Korkunov & 9 & - \\
Alpen Gold-tango & 10 & 1 \\
Alpen Gold-dark chocolate & 1 & - \\
\hline
\end{tabular}


The girls' gender-image preferences were clearly more varied than those of the boys. Most boys preferred the commercial for Snickers, which portrayed masculine male and female images in the context of their egalitarian (modern) relationships. None of the boys selected the commercial with a masculine male image and a feminine female image, which demonstrated traditional gender relationships. These results may mean that the boys were more oriented to modern relationships and masculine properties. In addition, in the Korkunov commercial the male image was closer by age to these adolescents' fathers, while in the commercial for Snickers the male image and the activity (basketball playing) were closer in age to the boys in the study than they were in the other commercials. In the Milka and Alpen Gold-dark chocolate commercials the male images did not take any energetic actions and did not display any of the bright characteristics that might promote boys' identification with them. At the same time, nine girls preferred the Korkunov commercial; this preference was probably caused by the male character's "father age" and can easily be explained by reference to psychoanalytical positions.

Certain tendencies in the adolescents' self-consciousness of gender characteristics and the connections of their selections are difficult to determine reliably from the point of view of statistics as the sample was not big enough and the boys did not make a variety of choices. The analysis of available variants was based on the adolescents' preferences in the commercials for images of a certain gender type. Gender characteristics of identity and changes in cognitive and emotive levels in the perception of gender semantics were detected in the images selected by each participant.

The girls whose choice of commercial was Milka had mostly feminine self-assessments. Consciousness on a cognitive level was gender-differentiated (male and female images were clearly separated). The male images were identified with the "an ideal man" image in the following order: "a traditional man," "my father," "a typical modern man." The female images were identified with the "an ideal woman" image in the following order: "my mother," "me in the future," "a traditional woman," "me in the present." After viewing the commercials and selecting the Milka plot as their favorite, the girls identified the image in the commercial that they liked best with "me in the present," "a traditional woman," "me in the future," "my mother"; these images also became closer to each other. Their assessment of the male images did not change significantly.

At the emotive level, consciousness was not differentiated by gender. In particular, the "me in the present" image was identified with "my father," "a traditional woman," "an ideal woman," "my mother," "a typical modern man," "an ideal man," and "me in the future." The "my father" image was close to both the female and male images. The "an ideal man" image was equated with "an ideal woman" and was close to "a typical modern man." The female image in the commercial was taken as an ideal feminine image that actualized the femininity of other female images in consciousness and enhanced the significance of femininity. "An ideal man" and "an ideal woman" became closer to the female images. After the girls selected a female image in the commercial as their favorite, the image of the father, which was close to the female images, became more feminine, and self-image became identified with female images to the highest degree. 
At the cognitive level the girls who chose the Snickers commercial identified their self-image with the "me in the future" image, which was close to "my mother," "an ideal woman," and "a traditional woman." Their self-image contrasted with all male images. The image of "my father" was closest to "an ideal man," "a traditional man," "a typical modern man" (0.88). After the girls watched the commercial, the impact of gender differentiation in consciousness at this level increased.

At the emotive level, the girls did not clearly differentiate gender consciousness: self-image was identified with both the female and the male images in the commercial. After watching the commercial, they identified their favorite gender image with "my father," "an ideal man," "a typical modern man," "a traditional man"; in other words, the image in the commercial that they liked best was a masculine image. The choice of the masculine image by these girls was correlated with a masculine mother's image at the emotive level of gender consciousness. In turn the girls took this image of the mother as an ideal after they watched the commercial. Thus, for these girls, their favorite image in the commercial became closer to their selfimage and enhanced the masculinity of the "me in the future" image.

At the cognitive level the girls who selected the Korkunov commercial had gender-differentiation enhancement: for them, the female and male images were opposed, and their self-identification with the female images was strengthened. In other words, watching the commercial increased the femininity of these girls' self-consciousness. For that reason, it is interesting to note that the girls selected a male image in the commercial as the one they liked; they identified this image with "an ideal man." At the emotive level, the changes were stronger than at the cognitive level. Their viewing of the commercial enhanced the "my mother," "an ideal woman," "my father," "an ideal man,", and "me in the future" images. The "me in the future" image was identified with their favorite image in the commercial. The identification with "an ideal woman" increased (coefficient was 0.38 , became 0.71). The change of identification with "an ideal man" image was the strongest: the coefficient became 0.52 , although the opposition had previously been -0.74 . On the emotive level, the image from the commercial that they most liked was perceived as an ideal, and this identity reinforced the value itself and its adoption by the girls.

The girls who selected the commercial for Alpen Gold-tango (androgynous images) did not have clearly differentiated gender consciousness at the cognitive level. Their self-image was identified with female images and was contrasted with male images, or was far from them. However, the image of the mother, for example, was equally close to the image of the "ideal woman" and the image of the "ideal man" and was also close to the image of "my father." Viewing the commercial and selecting their favorite image increased their gender differentiation in consciousness. The image in the commercial influenced perceptions of male images by making them more gender-typed. At the emotive level, the consciousness of these girls was clearly gender-typed: they identified with images of the same sex and contrasted them with images of the opposite sex. Viewing the commercial and choosing their favorite image increased their gender differentiation in consciousness significantly; all coefficients were close to extreme values (0.87-0.98).

The boys who selected the Snickers commercial had a more gender-differentiated consciousness at the cognitive level than did the other boys. Viewing this commercial and selecting their favorite image increased gender differentiation in 
consciousness. They identified the image in the commercial that they most liked with "a traditional man," "my father," "an ideal man," "a typical modern man," and "me in the future." The "my mother" image was opposed to this image as were all other female images. Their favorite image from the commercial was identified with the image of "an ideal man." The results indicated that the boys enhanced their ability to differentiate images based on gender after viewing the commercial.

These boys had non-gender-typed consciousness at the emotive level. At this level, self-identification was connected to a parent image. Self-image was identified with "me in the future" and was strongly identified with the image of "a typical modern woman" (0.78) and with "my father," "my mother," "an ideal man," and "an ideal woman." Identification with "my father" (0.59) was weaker than with "a traditional man" image (0.78). Viewing the commercial and selecting a favorite gender image increased the gender differentiation of self-consciousness at this level. For example, "a typical modern woman" became identified with "a traditional woman" (coefficient was 0.09 , became 0.77 ) and became contrasted with "a traditional man" (coefficient was 0.58 , became -0.09 ).

We also analyzed cases in which only one person preferred a commercial. The self-image of the girl who chose a masculine female image in the plot of the Alpen Gold-dark chocolate commercial was masculine. After she watched the commercial, her self-image became identified with her favorite gender image in it. Moreover the masculine female image in the commercial subjectively performed the role of ideal for female images. In other aspects gender differentiation in self-consciousness increased a little.

The boy who selected the Alpen gold-tango commercial (androgynous images) did not divide the images based on feminine/masculine grounds. His favorite image from the commercial was identified with "an ideal woman," "my mother," "a typical modern woman," and his self-image. The "me in the future" image began to be identified with the "my mother" image at the emotive level. Under the influence of the commercial, this boy's gender differentiation in consciousness increased, although it was still androgynous.

The boy who selected the commercial "Milka" was characterized by feminine self-consciousness both in self-evaluation and in identification with female images. After he had watched the commercial and selected an image from it (a female image was selected), his evaluation became more masculine, and his perception of other images came to be more gender differentiated. The female image from the commercial was taken as "an ideal woman," which in turn enhanced the masculinity of his gender self-consciousness.

\section{Discussion}

In general in our experiment changes that were the direct result of the impact of gender images in the commercials were characterized at the cognitive level of the girls by enhancement of identification with images of their gender, and at the cognitive level of the boys they were characterized by enhancement of consciousness of gender differentiation. At the emotive level, in contrast to the cognitive level, we observed stronger dynamics of the changes in self-consciousness (enhancement of gender differentiation and identification with gender ideals and parental images). 
The obtained data cannot be interpreted from statistically significant regularity positions. Nevertheless, the investigation showed the possibilities of using psychosemantic technology to diagnose self-consciousness in research work devoted the impact of images (in our case, these were advertising images) on consciousness structure and identification changes. The research clearly showed the quite high plasticity of self-consciousness structures and their susceptibility to externally designated images.

We also found that, despite different variants of the gender characteristics of the images, in which masculine female images, androgynous images, and feminine male images were presented, their impact on gender self-consciousness consisted mostly of gender differentiation and enhancement of identification with images of the same gender. These data are consistent with the findings of Sestir and Green (2010) that, under conditions of high identification with a character in a film, the traits that are displayed by this character are temporarily increased within participants' self-concept. Furthermore, it was also discovered that a change in gender self-consciousness under the influence of commercials does not necessarily occur through a recipient's identification with the image in the commercial. The semantics of an image in a commercial can play the role of "a launching mechanism" for identification processes with other images present in self-consciousness.

Probably the obtained results were influenced by the directed and specially arranged reflection of gender constructs; this reflection occurred because the adolescents rated the given gender images and focused their attention on the analysis and selection of images in the commercial. Richter and others (2014) investigated a similar effect: reading a story that featured a protagonist with a traditional gender role (focused on motherhood) increased femininity only among readers who were deeply transported into the world of the story.

We consider this research a pilot study and are planning to check the results on a more representative sample with different age groups.

\section{Conclusion}

In our research, we discovered that gender images in a commercial affect adolescents' gender self-consciousness only in the area of already-formed tendencies and categories. Individual differences in the perception of gender images in commercials by adolescents and in the effects on their gender self-consciousness are strong and depend on several factors related to the adolescents:

- degree of gender-differentiation self-consciousness

- self-identification with traditional or modern gender images

- gender identification

- perception of gender aspects transmitted by the commercials

- levels of self-consciousness at which the perception of the images in the commercials takes place (cognitive or emotive)

General trends are evident in the selective attention of adolescents to gender images linked to their gender self-categorization: masculine adolescents prefer 
masculine images in commercials; feminine adolescents focus on the femininity features of these images. Perception and evaluation of gender images in commercials affect changes in gender identity on both cognitive and emotive levels.

In the commercials the perception of gender images on a cognitive level mostly reinforced girls gender-role identity and made gender differentiation in boys' consciousness stronger. On an emotive level, changes in categorization were stronger and consisted in increasing identification with images of parents and of gender ideals.

\section{Acknowledgments}

We acknowledge and thank psychology students Tatiana Bychkova, Naila Gainieva, and Landysh Galimzjanova for their excellent work as research assistants on this project.

\section{References}

Barner, M. R. (1999). Sex-role stereotyping in FCC-mandated children's educational television. Journal of Broadcasting and Electronic Media, 43, 551-564. doi: 10.1080/08838159909364509

Bretl, D. J., \& Cantor, J. (1988). The portrayal of men and women in U.S. television commercials: A recent content analysis and trends over 15 years. Sex Roles, 18, 595-609. doi: 10.1007/ BF00287963

Collins, R. L. (2011). Content analysis of gender roles in media: Where are we now and where should we go? Sex Roles, 64, 290-298. doi: 10.1007/s11199-010-9929-5

Duncan, L. E., Peterson, B. E., \& Winter, D. G. (1997). Authoritarianism and gender roles: Toward a psychological analysis of hegemonic relationships. Personality and Social Psychology Bulletin, 23, 41-49. doi:10.1177/0146167297231005

Durkin, K. (1985). Television and sex-role acquisition 2: Effects. British Journal of Social Psychology, 24, 191-210. doi:10.1111/j.2044-8309.1985.tb00680.x

Eisenstock, B. (1984). Sex-role differences in children's identification with counter stereotypical televised portrayals. Sex Roles, 10, 417-430. doi:10.1007/BF00287558

Etkind, A. M., \& Bazhin, E. F. (2000). Tsvetovoy test otnosheniy [Color Test of Relationships]. St. Petersburg: IMATON.

Ganahl, D. J., Prinsen, T. J., \& Netzley, S. B. (2003). A content analysis of prime time commercials: A contextual framework of gender representation. Sex Roles, 49, 545-551. doi: 10.1023/A:1025893025658

Garst, J., \& Bodenhausen, G. V. (1997). Advertising's effects on men's gender role attitudes. Sex Roles, 36, 551-572. doi: 10.1023/A:1025661806947

Gerbner, G. (1999). The stories we tell. Peace Review, 11, 9-15. doi: 10.1080/10402659908426225

Gladkova, A. A. (2013). The role of television in cultivating the values of pluralism and cultural diversity in children. Psychology in Russia: State of the Art, 6,138-143. doi: 10.11621/ pir.2013.0113

Lavrova, E. V., \& Matveeva, L. V. (2012). Analysis of mass-media affected transformations of the danger concept. Psychology in Russia: State of the Art, 5, 301-313. doi: 10.11621/pir.2012.0018

Lopukhova, O. G. (2013). Oprosnik "Maskulinnost', feminnost' i gendernyi tip lichnosti” (rossiyskiy analog "Bem Sex Role Inventory") [The questionnaire "Masculinity, femininity and the gender type of personality" (the Russian analogue of the Bem Sex Role Inventory)]. Voprosy Psychologii [Issues in Psychology], 1, 147-154. 
Maksimova, O. B. (2005). Gendernoe izmerenie v sovremennom sotsialno-kommunikativnom diskurse: Rol reklamyi [The gender dimension in contemporary sociocommunicative discourse: The role of advertising]. Vestnik RUDN [RUDN Bulletin], 6/7, 246-254.

Morgan, M. (1982). Television and adolescents' sex-role stereotypes: A longitudinal study. Journal of Personality and Social Psychology, 43, 947-955. doi:10.1037/0022-3514.43.5.947

Oliver, M. B., \& Sargent, S. L. (1998). The impact of sex and gender role self-perception on affective reactions to different types of film. Sex Roles, 38,45-62. doi: 10.1023/A:1018760427785

Petrenko, V. F. (2010). Osnovy psychosemantiki [Fundamentals of psychosemantics] (3rd ed.). Moscow: Eksmo.

Pollay, R. W. (1986). The distorted mirror: Reflections on the unintended consequences of advertising. Journal of Marketing, 50, 18-36. doi: 10.2307/1251597

Richter, T., Appel, M., \& Calio, F. (2014) Stories can influence the self-concept. Social Influence, 9(3), 172-188. doi: 10.1080/15534510.2013.799099

Ruble, D. N., \& Stangor, C. (1986). Stalking the elusive schema: Insights from developmental and social-psychological analyses of gender schemes. Social Cognition, 4, 227-261. doi: 10.1521/ soco.1986.4.2.227

Sestir, M., \& Green, M. C. (2010). You are who you watch: Identification and transportation effects on temporary self-concept. Social Influence, 5, 272-288. doi:10.1080/15534510.2010. 490672

Signorella, M. L., \& Liben, L. S. (1984). Recall and reconstruction of gender-related pictures: Effects of attitude, task difficulty, and age. Child Development, 55, 393-405. doi: 10.2307/1129951

Signorielli, N. (1989). Television and conceptions about sex roles: Maintaining conventionality and the status quo. Sex Roles, 21, 341-360. doi: 10.1007/BF00289596

Original manuscript received October 10, 2014

Revised manuscript accepted February 24, 2015

First published online March 31, 2015 